Res Publica. Revista de Historia de las Ideas Políticas ISSN: $1576-4184$

\title{
La potencia de Marx
}

\section{A propósito de Carlos Casanova, Estética y producción en Karl Marx, Santiago de Chile, Metales Pesados, 2016, 118 pp.}

Rodrigo Karmy Bolton*

En mis palabras, se trata de devolverle a un acontecimiento la intempestividad que es suya, lo que implica hacerlo en una temporalidad no dada de antemano, sino tan inédita como el impacto de lo que aconteció

Guadalupe Santa Cruz

1. Pocas veces tenemos el privilegio de trabajar en torno a un escrito tan fino y riguroso. Estética y producción en Karl Marx de Carlos Casanova es uno de esos libros que nos hace libres, uno de esos pequeños gestos que todo lo transforman y modifican. Es éste, un libro que libra batallas, un texto que disloca formas y que pone al lector "(...) en relación con su propia capacidad de uso (y de no uso) de sus fuerzas activas (...)". ¿QQué significa usar un libro sino el movimiento de una libertad que ha dejado atrás cualquier captura soberana? Asumiendo la radicalidad de lo que significa pensar, Casanova nos abre a un Marx intempestivo. Como tal, un Marx que no calza con su espacio ni con su tiempo y que, en este sentido, resulta fiel a sí mismo en cuanto la "fidelidad" aquí comprometida se aleja de toda mímesis. No se trata de un Marx "aplicable" a una nueva época como si se tratara de un Marx "claro y distinto", universalmente válido a todo tiempo y lugar, sino de un Marx intempestivo que resguarda el temblor de su escritura a contrapelo del capital. Un Marx intempestivo es fiel a Marx, precisamente porque no le reproduce técnicamente, sino que lo usa libremente: “(...) la concepción antropológica — dice Casanova explicitando su tesis - de Marx es indivisible de una determinada concepción estética del hombre. Es aquí, a nuestro parecer, donde se debate la cuestión del «humanismo»y, ligada a ésta, la cuestión del «comunismo»" "2. La antropología de Marx implicará una noción estética del hombre. Pero "estética" ya no puede significar aquí una doctrina de lo bello, sino una problematización radical acerca de la historicidad de los sentidos. Porque, en rigor, para Casanova se trata de una lectura que vaya más allá de las dos lecturas que han predominado en el circuito contemporáneo: por un lado, no se trata de reivindicar a un Marx "humanista" en el sentido en que una vez sugirió Erich

Universidad de Chile

rkarmy@gmail.com

1 C. Casanova, Estética y producción en Karl Marx, Santiago de Chile, Metales Pesados, 2016, p. 7.

2 Ibidem, p. 8. 
Fromm, por otro, tampoco se trataría de sostener a un Marx "anti-humanista" como ha sido el santo y seña de la interpretación legada por Louis Althusser.

En un gesto que recuerda al buen Aristóteles, Casanova prueba una vía media entre ambas lecturas que, sin embargo, permita una fidelidad intempestiva de Marx. De esta forma, la mentada "antropología” de Marx se plantea bajo la noción de potencia en la que el hombre se resuelve cada vez, en relación a su propia "capacidad de uso (y no uso) de las fuerzas activas":

Es, en otras palabras, porque sólo existe en el modo de la potencia, de una potencia en acto que es, simultáneamente, acto de potencia, que se conserva y perdura, que insiste y resiste como tal potencia en el acto, que el hombre es, según Marx, ese ser que sólo existe en el modo de la praxis de sus sentidos, extrañado o apropiado y confinado a lo posible en esas praxis de sí3.

Casanova nos ofrece un párrafo cuya densidad es preciso comentar: lo que llamamos "hombre" no es más que una formación histórica que, sin embargo, no responde a la télos onto-teo-lógico de una potencia que necesariamente ha de resolverse en acto, pero tampoco de una potencia que jamás se actualiza frente a un acto que trabaja espectral. Ambas alternativas responden a la misma teleología de la potencia al acto, onto-teo-logía que deja en la sombra su propia historicidad, forma que sutura al mismo médium que la abre.

La potencia no será aquí un subrogado del acto, sino su verdad misma, su astillamiento histórico que adquiere consistencia ontológica: "La apropiación de la historicidad, es decir, la apropiación de acuerdo a la cual no hay forma que sea presupuesta, ya que mas bien es la forma misma la que no tiene otro presupuesto que su propia historicidad, su propio devenir metamórfico (... "). Lejos de la idea, según la cual, la forma estará presupuesta como un principio trascendente a la comunidad que la destina hacia una obra en particular, Casanova pone el énfasis en la dimensión desobrada del hombre, en la que ninguna misión, destino o principio determinan la vida humana; en otras palabras, el fundamento de toda forma no es más que el in-fundamento que cada forma encuentra en la dimensión potencial que la define. Nada más que potencia y, por tanto, ninguna naturaleza ni "forma presupuesta" más que la historicidad que designa al devenir metamórfico con el que la potencia abre la batalla de las formas. Si en Marx la forma no tiene otro presupuesto que su propia historicidad es porque toda forma se muestra como una verdadera prótesis que revela al intensidad de una potencia: relación con lo otro de sí, relación protésica de una potencia para con las formas, cuyo advenimiento sólo puede darse en el devenir en que cada forma no encuentra más presupuesto que la intensidad de sus potencias. Todo hombre está en relación "con su propia capacidad de uso (y de no uso)", no con su propiedad, todo hombre está siempre en la dimensión común de la potencia y nunca bajo el presupuesto de alguna forma. Prótesis y jamás naturaleza, potencia común y nunca simple antropología, definen los contornos de la historicidad radical en la que se escombra la dimensión absolutamente intempestiva del pensamiento de Marx. 
2. En contra del historicismo, Casanova ofrece un Marx intempestivo. Heredada clandestinamente por el "averroísmo", despertar a los avatares de la potencia que ha sido, una y otra vez, rechazada por los circuitos teológicos de la "providencia" y su figuración "secular" de la filosofía de la historia, la dimensión paria de Marx nos sitúa en la soledad de quien no recibe ayuda de los dioses, en la intemperie de quien carece de cualquier "garantía" que pudiera tranquilizar las conciencias. Ni estamos ganando, ni la historia está con nosotros. La verdad abismal es que leer a Marx hoy es ya un ejercicio revolucionario. Ganaron los "teólogos", otra vez, ahora en la forma incondicionada de la burguesía planetaria y su actual guerra civil global.

Porque así como Averroes lo hizo con los teólogos de su época, Spinoza con los suyos, Marx desafió a la historia y su nueva apuesta "teológica" cristalizada en la economía política moderna, liberando a la potencia común de la subjetivación capitalista que la restringe a la noción de "fuerza de trabajo". La obsesión de ésta última por fundar una vida común en base a un principio trascendente (la mercancía) será, sin embargo, la premisa histórica de su ruina, cuando la ontología de la potencia haga que las formas sociales encontrarán el desgarro de su historicidad:

La mercancía - dice Casanova - no sólo es una categoría en la que se expresa una relación de intercambio, sino ante todo, y de manera mucho más fundamental, una categoría en la que se expresa una forma específica (históricamente determinada) de determinación del ser social en el capitalismo, es decir, una determinada clase de mediación específica del capitalismo 5 .

Lejos de la lectura planteada por Jaques Derrida, según la cual, la crítica de Marx a la mercancía funcionaría como una crítica a toda "mediación", Casanova argumenta que se trata de afinar la crítica a una forma particular de mediación característica del capitalismo. Mediación, ésta, que reduce toda la existencia social a un mismo régimen de equivalencia general. Para Marx, se trata de atender a una ontología histórica en la que se escombre una crítica de la forma mercancía como última metafísica de lo social, último "ídolo" sin el cual, el capitalismo no podrá funcionar:

A primera vista - escriben Marx y Engels en un célebre apartado de El Capital parece como si las mercancías fuesen objetos evidentes y triviales. Pero analizándolas, vemos que son objetos muy intrincados, llenos de sutilezas metafísicas y de resabios teológicos Considerada como valor de uso, la mercancía no encierra nada misterioso (...) Pero, en cuanto empieza a comportarse como mercancía, la mesa se convierte en un objeto físicamente metafísico ${ }^{6}$.

En contra de esa potencia averroista-spinozista-marxista en la que se juega el "valor de uso" y en donde las formas acaecen como posibles; el capitalismo habría suturado al ser-de-potencia en una forma absolutamente necesaria: la mercancía. El uso ya no será posible, sino tan sólo la cambiabilidad mercantil, la libertad será capturada desde la propiedad privada, y el poder común será reducido a la explotación mundial del trabajo. Exactamente como proponía en su momento la teología asharí, el problema del capi-

6 K. Marx y F. Engels, El Capital. Crítica de la economía política I, México DF, Fondo de Cultura Económica, pp. 36-37. 
talismo reside en la restricción de la dimensión an-árquica de la potencia en la forma teleológica de una "fuerza de trabajo" en la que la potencia (lo que el discurso burgués llama "talento") pasa al acto (la "obra" en particular): nunca habremos de identificar la potencia con la "fuerza de trabajo", sino atender la captura "estética" ejercida por el capitalismo, por suturar el libre desenvolvimiento de los sentidos, en el que se arraiga esa potencia común, en los "resabios teológicos" de la misma forma mercancía.

La potencia no será esencialmente "fuerza de trabajo" a no ser que la forma mercancía, tal como otrora lo hicieron los teólogos, la capture, restringiéndola a una "obra" en particular:

Como si más allá de cualquier actividad particular —escribe Casanova— aún se le reservara al hombre una función, una obra que les es propia más allá de toda obra específica: la función del hombre — responde la metafísica del capital— consiste en una «cierta vida», la vida productiva. Como si el capitalismo - termina Casanova - hiciera de la ausencia de obra del hombre, su propia obra, su propio poder o potencia. Este poder no es otro que la fuerza de trabajo, que el capitalismo distingue efectivamente de todo trabajo efectivo ${ }^{7}$.

Clave pasaje al que nos invita Casanova, donde lo que está en juego es precisamente la captura de dicha potencia, del médium en la reducción "teológica" de la potencia social a una función o una obra que determinaría la división social del trabajo y que, a su vez, hará de la vida humana una vida entera y necesariamente producti$v a$. Sólo porque la "metafísica del capital" considera a cada hombre una "fuerza de trabajo", hace del desobramiento humano su verdadera obra. Con ello, erige nuevos trascendentales, que Marx desmonta para: "(...) devolverlos a la inmanencia de la

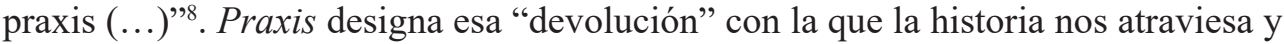
en la cual, en una suerte de epoché, la subjetivación capitalista que nos ha dispuesto como "fuerza de trabajo" queda radicalmente destruida.

Se trata de un espacio-tiempo - escribe Casanova- que no es el de la labor, tampoco el de descanso, ni menos el privado que les corresponde como miembros de una familia o como precarios consumidores; en él ellos ejercen un conjunto de capacidades que ya no están dispuestas para la productividad del capital. Espacio-tiempo común de liberación y de reformulación —-mediante la reapropiación o uso de las fuerzas - de las relaciones establecidas entre hacer y hablar, desear $y$ pensar ${ }^{9}$.

El comunismo abre el lugar de la potencia que no es "labor" ni "descanso", sino un modo de vivir-en-uso, un modo de vivir-libres, donde uso coincide con libertad. El comunismo es un movimiento efectivo que, a diferencia de todos los demás movimientos, está completamente exento de algún principio claro y distinto. El comunismo no puede, por esta razón, ser más que la an-arquía de la vida común.

Una vida que ha renunciado a ser fundamentada en base a un principio trascendente y donde no hay nada más que el carácter protésico de una potencia capaz de

C. Casanova, op. cit., p. 90.

Ibidem, p. 39.

Ibidem, p. 110. 
devenir múltiples formas sin reducirse a ninguna de ellas en particular. Ni persona, sujeto o conciencia, el comunismo puede ser pensado como la violencia de un encuentro entre los hombres y su potencia común, de lo humano con lo inhumano, de un proletariado que no es una "clase" sociológicamente administrada, sino una "no-clase" política e históricamemte clave. Proletariado designa aquí un vacío o una potencia, antes que "algo" claramente establecido y el comunismo, una interrupción que depone radicalmente la división del trabajo, desobrando a la vida común. Ni amo ni esclavo, ni patrón ni asalariado, el comunismo se desenvuelve como la violencia histórica de una no-clase (el proletariado) que destruye la misma división de clase, la apropiación última que destruye toda apropiación.

Comunismo es, por esto, el nombre de un oxímoron: el de un humanismo desobrado que juega a contrapelo del humanismo obrado fomentado por la burguesía, el de un ser-de-potencia que prescinde de toda obra y que, por tanto, hace saltar por los aires al ser-en-obra del capital. Dicho con las palabras que Giorgio Agamben ha reservado para el último libro de la saga Homo Sacer, El uso de los cuerpos - un autor clave en la lectura que ofrece Casanova - podríamos decir que el comunismo es el movimiento de una apropiación de lo inapropiable en la que necesariamente, juega en la impersonalidad de lo común. Sólo por eso, dicha apropiación destruye a toda apropiación y abre a los hombres a sus capacidades de uso (o no uso), a sus potencias. 